\title{
CONSIDERACIONES SOBRE LOS \\ FUNDAMENTOS DEL PRINCIPIO \\ DE SUBSIDIARIDAD
}

(Una aproximación) *

\author{
Eduardo Soto Kloss \\ Profesor de Derecho Administrativo \\ Facultad de Derecho - Universidad de Chile
}

"Dios ha ordenado que el hombre tienda espontáneamente a la sociedad civil, exigida por la propia naturaleza humana. En el plan del Creador, la sociedad civil es un medio natural del que cada ciudadano puede y debe servirse para alcanzar su fin, ya que el Estado es para el hombre y no el hombre para el Estado (civitas homini, non homo civitati exsistit). Esta última afirmación, sin embargo, no debe ser entendida en el sentido del llamado liberalismo individualista, que subordina la sociedad a las utilidades egoístas del individuo; sino sólo en el sentido de que, mediante la ordenada unión orgánica con la sociedad, sea posible para todos, por la mutua colaboración, la realización de la verdadera felicidad terrena, y además, en el sentido de que en la sociedad hallen su desenvolvimiento todas las cualida-

*Tratamos en estas Consideraciones sólo los fundamentos del principio de subsidiariedad, según los hemos extraido del pensamiento pontificio, de León xil a Pío xIr. Constituyen cllas -como decimos en el título- una "aproximación", ya que es solamente la introducción de un estudio que estamos realizando sobre el refcrido principio.

Publicamos aquí una parte de esa' Introducción, omitiendo los párrafos concernientes al pensamiento pontificio postcrior (Juan xxil a Juan Pa. blo II), ya que las bases esenciales han sido asentadas por los textos de aquellos grandes pontifices, los verdaderos artifices del principio.

Hemos usado para los textos pontificios los tomos II y II de Doctrina Pontificia (Biblioteca de Autores Cristianos), Documentos politicos. Madrid. 1958, y Documentos sociales. Madrid. 1959. Aqucllos textos que no van referidos a la obra precedente han sido consultados en R. González Moralcjo, Pensamiento pontificio sobre el bien común. Euramérica. Madrid. 1956. 
des individuales y sociales insertas en la naturaleza humana, las cuales superan el interés particular del momento y reflejan en la sociedad civil lá perfección divina; cosa que no puede realizarse en el hombre separado de toda sociedad. Pero también estos fines están, en último análisis, referidos al hombre, para que, reconociendo éste el reflejo de la perfección divina, sepa convertirlo en alabanza y adoración del Creador. Sólo el hombre, la persona humana y no las sociedades, sean las que fueren, está dotado de razón y voluntad moralmente libre"1.

Y es que "el hombre en su ser personal no está subordinado a la utilidad de la sociedad, sino, por el contrario, la comunidad es para el hombre. La comunidad es el gran medio querido por la naturaleza y por Dios para regular los cambios en que se completan las necesidades reciprocas, para ayudar a cada uno a desarrollar completamente su personalidad, según sus aptitudes individuales y sociales"2.

Pues que es indudable que el hombre, por su naturaleza misma, si bien está destinado a vivir en sociedad, ello no significa que el hombre haya sido hecho para la sociedad, sino por el contrario la sociedad existe para la perfección del hombre, de todos y cada uno de sus miembros que la componen, puesto que son personas: "la sociedad no ha sido instituida por la naturaleza para que el hombre la busque como su fin último, sino para que en ella y por medio de ella posea medios eficaces para su propia perfección"3.

Si, porque hay un fin inmediato para el hombre -cuerpo y espiritu, cuerpo corruptible y alma inmortal- cual es el cultivo y desarrollo pleno de todas sus facultades, y el cumplimiento fiel de los deberes de su profesión o de su vocación, sea cual fuere, lo que le dará ciertamente una felicidad temporalt. $Y$ también un fin último, "ya que todos cuantos hemos venido a la luz de este mundo nos reconocemos naturalmente inclinados y razonablemente movidos a la consecución de un bien último y supremo, por encima de la fragilidad y brevedad de esta vida"5, fin último que no es otro que Dios.

'Pío x1, Divini Redemptoris (19.3.1937) parágr. 29 (en DP 686-687).

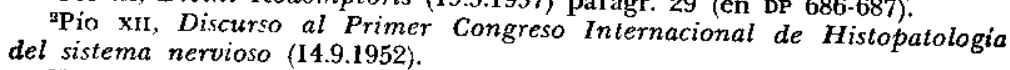

'León XIII, Sapientiae Christianae (10.1.1980) parágr. 2 (en DP 265).

"Vid Pío XI, Quadragesimo Anno (15.5.1931) parágr. 118 (en Ds 265).

'León xIII, Immortale Dei (1.11.1885) parágr. 3 (en DP 194). 
$\mathbf{Y}$ estas afirmaciones no son puramente gratuitas, no constituyen el fruto de un lirismo apasionado o de un optimismo desenfrenado; no, en modo alguno. Son basadas y tienen su fundamento en la naturaleza misma del hombre (en cuanto ser racional, libre, sociable y contingente) y de la sociedad o sociedades (agrupaciones naturales y artificiales) en que él nace y actúa, o que él mismo crea, dada su natural socialidad, su tendencia o inclinación natural a vivir con otros y para otros.

Es un dato de la realidad y de la diaria experiencia, que cualquiera puede comprobar con la luz natural de su razón, que "el hombre está ordenado por la naturaleza a vivir en comunidad. El hombre no puede procurarse en la soledad todo aquello que la necesidad y la utilidad de la vida corporal exigen, como tampoco lo conducente a la perfección de su espiritu. Por esto la providencia de Dios ha dispuesto que el hombre nazca inclinado a la unión y asociación con sus semejantes, tanto doméstica como civil"6.

$Y$ es Dios mismo quien ha ordenado que el hombre tienda espontáneamente a la sociedad civil, exigida por la propia naturaleza humana, sociedad civil que es un medio natural que cada ciudadano debe aprovechar para alcanzar su propio fin?.

Pero tal sociedad civil no ha sido instituida por la naturaleza para que el hombre la busque como fin último de su existencia, sino para que en ella y por medio de ella pueda encontrar medios eficaces para su propia perfeccións. El Creator ha querido la sociedad "como medio para el pleno desenvolvimiento de las facultades individuales y sociales (del hombre) del cual medio tiene que valerse el hombre, ora dando, ora recibiendo, para el bien propio y el de los demás"9.

'León XII, Immortale cit. prágr. 2 (en DP 19I).

'Pío XI, Divini Redemptoris cit. parágr. 29.

${ }^{3}$ León XIII, Sapientiae cit. parágr. 2.

'Pío XI, Mit Brennender Sorge (14.3.1937) parágr. 35 (en dP 659) Pío xII (Radiomensaje al vi Congreso Internacional de Médicos Católicos, (11.9. 1956) pondrá muy bien de relieve esta característica de "medio" que ticne la sociedad: "El individuo recibe este derecho (se refiere el Papa al derecho a la vida, a la integridad del cuerpo y de la vida, a los cuidados que le son necesarios a ser protegido de los peligros que le amenazan) ante todo en sí mismo y para si mismo; después, en relación con los demás hombres y con la sociedad, y esto no solamente en el orden de la acción presente 
$\mathbf{Y}$ es que "origen y fin esencial de la vida social ha de ser la conservación, el desarrollo y el perfeccionamiento de la persona humana"10.

Cada persona y cada sociedad particular en la organización social tiene $-y$ esto es un dato que la razón natural percibe y capta a poco que medite en ello- un puesto determinado y digno, y sabı, para hablar sólo de la sociedad más importante, el Estado, que su actividad, política y económica, "cstá sometida a la realización permanente del bien común, es decir de aquellas condiciones externas que son necesarias al conjunto de los ciudadanos para el desarrollo de sus cualidades y de sus oficios, de su vida material, intelectual y religiosa"11.

Ello aparece evidente, porque "cuando, sin renunciar a los deberes y derechos de la sociedad doméstica, varias familias se unen, guiadas por la naturaleza, para constituirse en miembros de otra familia más extensa, llamada sociedad civil, su fin no es solamente hallar en ésta medios para mejor proveer a su bienestar material, sino principalmente procurar por medio de ella el beneficio supremo, que es el perfeccionamiento moral de los ciudadanos. De lo contrario, la sociedad humana aventajaría muy poco a la reunión de seres irracionales, cuya existencia total se reduce a la satisfacción de los apetitos sensitivos. Pero hay más todavía: sin el afán de obtener este perfeccionamiento moral sería muy difícilmente demostrable que la sociedad civil, en

sino también en el de la finalidad. Sería apartarse del perisamiento de los Papas, claramente expresado, considerar al hombre en su relación con la sociedad como si estuviera inserto "en el pensamiento orgánico del organismo físico"; un miembro físico particular tiene, sin duda, una cierta existencia propia, pero, como tal, no existe en forma alguna por sí mismo; está absorbido finalmente por el conjunto del organismo. El principio "civitas propter cives, non cives propter civitatem" es una herencia antigua de la tradición católica y fue acogida en la enseñanza de los Papas León $\mathrm{xII}$, Pío $\mathrm{x}$ y Pío $\mathrm{xI}$, no de manera ocasional sino en términos explícitos, terminantes y precisos".

${ }^{10}$ Pío XII. Con sempre (24.12.1942) parágr. 9 (en DP 843).

IIdem, parágr. 13 (en DP 844). Bien común de orden temporal (el fin propio del Estado) que Pío xI en su Divini illud magistri (31.12.1929), pa. ragr. 36 (en DP 545) refería como "una paz y seguridad de las cuales las familias y cada uno de los individuos puedan disirutar en el ejercicio de sus derechos, y al mismo tiempo en la mayor abundancia de bienes espirituales y temporales que sea posible en esta vida mortal mediante la concorde colaboración activa de todos los ciudadanos". 
vez de constituir para el hombre, considerado como tal, una ventaja, no constituiría para él un grave daño"12.

$Y$ es que "la naturaleza, en efecto, nos ha dado no sólo el ser físico, sino también el ser moral. Por lo cual el hombre busca en la tranquilidad del orden público, fin inmediato de la sociedad civil, el bienestar $y$, sobre todo, los medios necesarios para perfeccionar su vida moral, perfección que no consiste en otra cosa que en el conocimiento y práctica de la virtud"13.

Esa sociedad en la cual viven los hombres implica de suyo una convivencia social, convivencia que tiene su origen en la voluntad de paz, y que tiende casi instintivamente, podría decirse, a la paz ${ }^{14}$. La paz -y aqui, paz social- nos recuerda el pensamiento clásico, no es sino esa tranquila convivencia en el orden ${ }^{15}$, y orden justo (valga la tautología, pues un orden injusto no es propiamente un orden). Supone, pues, convivencia en el orden, orden que, "base de la vida social de los hombres, es decir de seres intelectuales y morales, que tienden a realizar un fin conforme a su naturaleza, no es una mera yuxtaposición extrínseca de partes numéricamente distintas; es más bien, y debe ser, la tendencia y la realización cada vez más perfecta de una unidad interior, que no excluye las diferencias fundadas en la realidad y sancionadas por la voluntad del Creador"10.

La vida social exige, pues, de por sí unidad interior, unidad que en el espacio a ella asignado y según sus peculiares condiciones, tiende mediante la colaboración de los diferentes grupos, profesiones y sectores de la sociedad, a esa armonía social que tan indispensable es para alcanzar la tranquilidad en el orden que constituye la paz.

Esa unidad interior "no excluye, sin embargo, las diferencias causadas por la realidad y la naturaleza"; "tanto las semejanzas como las diferencias de los hombres encuentran un lugar adecuado en el orden absoluto del ser, de los valores $\mathrm{y}$, por consiguiente, también de la moralidad"'17.

12León XIII, Au milieu des sollicitudes (16.12.1892) parágr. 5 (en DP 300).

${ }^{23}$ León XIII, Sapientiae cit. parágr. 16 (en DP 283).

${ }^{14}$ Pío XII, Con sempre cit. parágr. 5 (en DP 842).

${ }^{1-S a n t o ~ T o m a ́ s ~ d e ~ A q u i n o, ~ S u m a ~ T e o l o ́ g i c a ~ 2-2, ~ q .29 ~ a r t . ~} 1$ ad 1.

${ }^{10}$ Pio $\mathrm{XII}$, Con sempre cit. parágr. 6 (en DP 842).

${ }^{17}$ Idem, parágr. II (en DP 84.3). 
$\mathrm{Y}$ es que "en un pueblo digno de este nombre, todas las desigualdades, derivadas no del capricho, sino de la naturaleza misma de las cosas, desigualdades de cultura, de riquezas, de posición social -sin perjuicio, naturalmente, de la justicia y de la mutua caridad- no son, en realidad, obstáculo alguno para que exista y predomine un auténtico espíritu de comunidad y fraternidad. Más aún, esas desigualdades naturales, lejos de menoscabar en modo alguno la igualdad civil, confièren a ésta su legítimo significado, esto es, que, frente al Estado, cada ciudadano tiene el derecho de vivir honradamente su propia vida personal"'18.

Valga recordar en este punto que "tres son las sociedades necesarias, distintas, pero armónicamente unidas por Dios, en el seno de las cuales nace el hombre: dos sociedades de orden natural, la familia y el Estado; la tercera, la Iglesia, de orden sobrenatural". "La familia, instituida inmediatamente por Dios para su fin específico, que es la procreación y la educación de la prole; sociedad que por esto mismo tiene prioridad de naturaleza $y$, por consiguiente, prioridad de derechos respecto del Estado", pero que no asume la calidad de sociedad perfecta "pues no posee en si misma todos los medios necesarios para el logro perfecto de su fin propio; en cambio, el Estado es una sociedad perfecta, por tener en sí mismo todos los medios necesarios para su fin propio, que es el bien común temporal"19.

Pero la natural socialidad humana -insita en su propia naturaleza, y que no radica en un mero utilitarismo, referido a la exterior necesidad de los demás, sino que se afinca en el ser mismo del hombre- lleva al ser humano a asociarse con sus congéneres en los innumerables ámbitos de su vida societaria, y para un mejor logro de sus fines ${ }^{20}$.

1sPío XII, Benignitas et Humanitas (24.12.1944) parágx. 18 (en DP 876). Pues no ha de olvidarse - como lo señala el Papa Pacelli (parágr. 11, en DP 875 ) - que el hombre, la persona, "lejos de ser el objeto y un elemento puramente pasivo de la vida sociai, es, por el contrario, y debe ser y permanecer, su sujeto, su funclimento y su fin"

${ }^{19}$ Pío XI, Divini illud cit. parágr. 8 (en DP 531s). Desde este punto de vista, o sea en orden al bien común temporal, el Estado tiene preeminencia sobre la familia, la cual alcanza solamente dentro del Estado su conveniente perfección temporal.

'xcón xill en su famosa Rerum Novarum (15.5.1891) parágr. 35 recuerda que "así como el instinto natural mueve al hombre a juntarse con otros para formar la sociedad civil, así también le inclina a formar otras socie- 
Esas sociedades o agrupaciones, frutos del natural derecho a asociarse con otros hombres, van formando un tejido asociativo que se extiende en el vasto panorama de los diferentes planos en que se mueve el hombre; sociedades, cuerpos y asociaciones que constituyen ese campo intermedio entre la persona y su familia, por una parte, y el Estado por la otra"'21.

Esa trama de sociedades, grupos o asociaciones, que conforman una comunidad civil o social ha, necesariamente, de poseer una unidad armónica y coherente, para que puedan tender todas ellas al bien común del Estado; la genuina misión y peculiar del poder político consiste precisamente "en promover eficazmente esa armoniosa coordinación de todas las fuerzas sociales" 22 .

$\mathrm{Y}$ es que toca al hombre ser artífice de su propio destino, dueño como es de sus propios $\operatorname{actos}^{23}$, al ser libre y por ende responsable.

dades, particulares, pequeñas e imperfectas, en verdad, pero verdaderas sociedades. Naturalmente que entre estas sociedades y la sociedad civil median grandes diferencias a causa de sus diferentes fines próximos. El fin de la sociedad civil es universal, pues se refiere al bien común, al cual todos y cada uno de los ciudadanos tienen derechos en la debida proporción. Por esto dicha sociedad recibe el nombre de pública, pues que mediante ella se unen los hombres entre sí a fin de formar o constituir un pueblo o Estado. Por el contrario, las demás sociedades que se forman en su seno, se consideran y son sociedades privadas, ya que su finalidad inmediata es el bien privado o particular de sus socios o miembros".

ma"Esta sociabilidad del hombre - dirá Pío xII en Carta de la Secretaría de Estado a la xvi Semana Social de España (Sevilla - 8.5.1956) - se concreta en ser miembro de dos sociedades necesarias, la familia y el Estado, y de otras formadas libremente. Por el hecho de pertenecer a esta sociedad, y en la debida proporción, los individuos han de tener conciencia, para acomodar a ella sus actos, de que además de sus intereses personales, existen los intereses colectivos; que junto al bien propio, está el bien común, al que todos deben cooperar, dentro del ámbito de la sociedad de que forman parte".

"Pio xI, Divini Redempioris cit. parágr. 31 (en DP 689).

«"Señor de si mismo" en la profunda expresión de Santo Tomás de Aquino (Suma Teológica 1-2, q. 1 art. 1 respondeo: "El hombre difiere de las criaturas irracionales en que es duenio de sus propios actos" -0 señor de sí mismo/quod est suorum actuum dominus). Y es que el hombre es dueño de sus actos gracias a la razón y a la voluntad; de allí que "los seres dotados de razón se mueven por sí mismos a un fin merced al dominio de sus actos que les presta el libre albedrío, facultad de la voluntad y de la razón" (Suma, cit. 1-2,q. 1 art. 2 'respondeo). 
$Y$ es que toca a él, y a las asociaciones que él constituya al asociarse con sus semejantes, forjarse su propio bienestar, perfeccionar las propias virtualidades que porta como persona, y progresar en su vida individual y social.

"Aquello que los individuos particulares pueden hacer por sí mismos y con sus propias fuerzas no se les debe quitar y entregar a la comunidad; principio que tiene igual valor cuando se trata de sociedades o agrupaciones menores y de orden inferior respecto de las mayores y más elevadas. Porque toda actividad social es por naturaleza subsidiaria; debe servir de sostén a los miembros del cuerpo social, y no destruirlos y absorberios" 24 .

La misión del Estado - bien común de la sociedad política- "es la de vigilàr, ayudar y ordenar las actividades privadas e individuales de la vida nacional, para hacerlas converger armoniosamente hacia el bien común"25; no es su misión, en consecuencia, y en principio, "la de asumir directamente las funciones económicas, culturales y sociales que pertenecen a otras competencias"26, "porque si el Estado se atribuye y apropia Ias iniciativas privadas, estas iniciativas - que se rigen por múltiples normas peculiares y propias- pueden recibir daño, con detrimento del mismo bien público, por quedar arrancadas de su recta ordenación natural, que es la actividad privada responsable" 27 .

"Su misión es más bien asegurar la verdadera independencia de su autoridad, de forma que pueda otorgar a todo cuanto en el país represente un poder efectivo y valioso una justa parte de responsabilidad, sin peligro para su propia misión de coordinar y de orientar todos los esfuerzos hacia un fin común superior"28. Su misión es "fácilitar a la persona, en esta vida presente, la consecución de su perfección física, intelectual y moral, y para ayudar a los ciudadanos a 1019).

24Pío XII, La elevatezza (20.2.1946) parágr. 9 (en DP 923).

${ }^{2}$ Pío XII, Crisis de poder y crisis de civismo (14.7.1954) parágr. 7 (en DP

2Pio XII, Crisis cit. parágr. 15 (en DP 1022).

2TPí XII, Summi pontificatus (20.10.1939) parágr. 47 (en DP 778). ${ }^{2}$ Pío xII, Crisis cit. parágr. 15 cit. Agrega sabiamente el gran Papa ju-
rista, en aquella época (1954), la necesidad de aceptar la participación: "para realizar una mejor integración de ciertos organismos intermediarios en la comunidad nacional pudiera a veces parecer oportuno llamarlos a una colaboración más estrccha y más orgánica con los poderes públicos' (idem). 
conseguir el fin sobrenatural, que constituye su destino supremo"20. Noble misión, pues, la del Estado: "reconocer, regular y promover en la vida nacional las actividades y las iniciativas privadas de los individuos; dirigir convenientemente estas actividades al bien común, el cual no puede quedar determinado por el capricho de nadie ni por la exclusiva prosperidad temporal de la sociedad civil, sino que debe ser definido de acuerdo con la perfección natural del hombre, a la cual está destinado el Estado por el Creador como medio y como garantía"30.

"Doble es, por consiguiente, la función de la autoridad política del Estado: garantizar y promover; pero no es en modo alguno función del poder político absorber a la familia y al individuo o subrogarse en su lugar"31.

$Y$ siendo esa su misión, concreción del bien común, misión de garantía y de promoción para el bien de todos los ciudadanos ${ }^{32}$, su for-

${ }^{20}$ Pio xII, Summi, cit. parágr. 44 (en Dr 777). Ya que el fundamento de todo orden social es la justicia, no debiendo ahorrarse esfuerzo alguno a fin de que todos los ciudadanos, hasta el último, puedan vivir en condiciones por lo menos tolerables; y es que toda la vida pública ha de mirar a promover el bien común y nos los intereses particulares de un partido - de una clase (Pío XIr, Discurso al Movimiento de la vanguardia católica italiana - 4.1.1948).

soldem, parágr. 45. Agrega lúcidamente este sapientísimo Pontifice: “El que considera el Estado (parágr. 46) como fin al que hay que dirigirlo todo $y$ al que hay que subordinarlo todo, no puede dejar de dañar y de impedir la auténtica y estable prosperidad de las naciones. Esto sucede lo mismo en el supuesto de que esta soberanía ilimitada se atribuya al Estado como mandatario de la nación, del pueblo o de una clase social, que en cl supuesto de que el Estado se apropie por sf mismo esa soberanfa, como dueño absoluto y totalmente independiente".

s1Pfo XI, Divini illud cit. parágr. 36 (en DP 545).

"Quienes gobiernan los Estados entiendan que el poder polftico no ha sido instituido para el provecho de un particular, y que el gobierno de la república no puede ser ejercido para utilidad de aquellos a quienes ha sido encomendado, sino para bien de los súbditos que les han sido confiados" (León XIII, Diuturnum illud (29.6.1881) parágr. 12, en DP 117).

"Por ello ha de ejercitarse en provecho de los ciudadanos, porque la única razón legitimadora del poder es precisamente asegurar el bienestar público. No se puede permitir en modo alguno que la autoridad civil sirva al interés de uno o de pocos, porque ella está constituida para el bien. estar de todos" (Immortale Dei cit. prágr. 2, en DP 192). Y repetirá León xill en su Rerum Novarum (parágr. 24, en Ds 336), que "Entre los muchos 
ma de actuar en las variadas actividades en que ha de preocuparse, ha de ser tanto en garantía de ese bien común como de promoción de él.

De garantía, en cuanto su finalidad esencial (el bien común de la soçiedad política) le exige "tuíelar el intangible campo de los derechos de la persona humana y facilitarle el cumplimiento de sus deberes. ¿No es acaso esto lo que lleva consigò el significado genuino del bien común, que es lo que el Estado debe promover?'33.

Dentro de este campo aparece esencial el respeto al derecho de asociación al que el natural carácter social de la persona le inclina: "estas sociedades privadas, aunque existan dentro del Estado y sean como otras tantas partes suyas, sin embargo, en general y absolutamente hablando, no las puede prohibir el Estado en cuanto a su existencia. Porque el hombre tiene derecho natural a formar tales sociedades, mientras que el Estado ha sido constituido para Ia defensa y no para el aniquilamiento de él; por lo tanto, si tratara de prohibir las asociaciones de los ciudadanos, obraría en contradicción consigo mismo, pues tanto él (Estado) como las asociaciones privadas nacen de un mismo principio, esto es, la natural sociabilidad del hombre"34.

y muy graves deberes de los gobernantes solícitos del bien público, se destaca entre los primeros el de prover por igual a todas las clases sociales obscrvando con inviolable imparcialidad la justicia distributiva".

sáo xu, La solemnila. En el cincucnteriario de la Rerum Novarum (1.6.1941) parágr. 15 (cn DS 957). Pero “cl cuiclado de este bien común -agrega Pío Xu- no lleva consiga un poder tan cxtenso sobre los micmbros de la comunidad, que en su virtud sea permitido a la autoridad pública disminuir el clesenvolvimicnto de la acción individual, decidir directamente sobre el principio o término de la vida humana (excluido el caso de legitima pena), determinar de propia iniciativa cl modo de su movimiento físico, espiritual, religioso y moral en oposición con los deberes y derechos personales del hombre, y con tal intento abolir o quitar su cficacia al derecho natural de bienes materiales. Deducir extensión tan grande de poder del cuidado del bien común, significarla atropellar el sentido mismo del bien común y caer en el error de afirmar que el fin propio del hombre en la tierra es la sociedad, que la sociedad es el fin de sí misma, y que el hombre no tiene que esperar otra vida fuera de Ia que se termina aquí abajo".

${ }^{3}$ León XıII, Rerum Novarum cit. parágr. 35 (en Ds 350). Ello, ciertamentc, sin perjuicio -y el texto citado continúa- que si algunas sociedades "tengan un fin contrario a la honradez, a la justicia, 0 a la seguridad de 
"El Estado no puede absorber al individuo ni a la familia; cada uno conserva y debe conservar su libertad de movimientos, en la medida en que no quede en peligro el causar perjuicio al bien común"35.

$\mathrm{Y}$ es que tal absorción es contraria a la naturaleza misma del hombre, y de su eminente dignidad de persona, creada a imagen y semejanza del Creador.

En efecto, "a causa del vicio del individualismo, las cosas han llegado ya a tal punto que, abatida y casi extinguida aquella exuberante vida social que otrora se desarrollara en las corporaciones o gremios de todas clases, han quedado casi solos frente a frente los particulares y el Estado. Semejante deformación del orden social lleva consigo no pequeño daño para el mismo Estado, sobre el cual vienen a recaer todas las cargas que antes sostenían las antiguas corporaciones, viéndose él abrumado y oprimido por una infinidad de cargas y obligaciones". "La mudanza de las condiciones sociales hace que muchas cosas que antes hacian aún las asociaciones pequeñas, hoy no las pueden ejecutar sino las grandes colectividades. Sin embargo, sigue en pie y firme en la filosofía social aquel importantísimo principio que ni puede ser suprimido ni tampoco alterado (quod neque moveri neque mutari potest): como es ilicito quitar a los individuos y darlo a la comunidad lo que ellos pueden realizar con su propio esfuerzo o iniciativa e industria, del mismo modo que es injusto y al mismo tiempo de grave perjuicio y perturbación para el recto orden social quitar a las comunidades menores o inferiores lo que ellas pue-

la sociedad civil, el Estado tiene derecho a oponerse a ella, ora prohibiendo que se formen, ora disolviendo las ya constituidas; pero aún entonces necesario es proceder siempre con suma cautela para no perturbar los derechos de los ciudadanos y para no realizar el mal so pretexto del público bien. Porque las leyes no obligan sino en cuanto están conformes con la recta razón, y, por lo tanto, con la ley eterna de Dios" (idem).

${ }^{25}$ Pío XII, La verdadera noción de Estado. Discurso al Congreso Internacional de Ciencias Administrativas (5.8.1950), en DP 978. Se pregunta el Papa y se responde en seguida: “¿Cuál es, pues, la verdadera noción de Estado sino la de un organismo moral fundado en el orden moral del mundo? No es una competencia opresora de toda legítima autonomía. Su función, su magnífica función, es más bien favorecer, ayudar, promover la intima coalición, la cooperación activa, en el sentido de una unidad más alta, de los miembros que, respetando su subordinación al fin del Estado, cooperan de la mejor manera posible al bien de la comunidad, precisamente en cuanto conservan y desarrollan su carácter particular y natural". 
äen nacer y procurar, para confíario a una socieâaã mayor y más eỉevada, ya que toda acción de la sociedad debe, por su propia fuerza y naturaleza, prestar ayuda o auxilio a los miembros del cuerpo social, pero nunca destruirlos y absorberlos"36.

"Conviene, por consiguiente, que la autoridad pública suprema deje a las asociaciones inferiores tratar por sí mismas aqueilos asuntos y negocios que ellas puedan resolver, de menor importancia, en los cuales por lo demás perdería mucho tiempo o le serian de grandísimo impedimento para cumplir con mayor libertad, firmeza y eficacia cuanto a ella sola corresponde, pues de su exclusiva competencia, a saber: dirigir, vigilar, estimular, neprimir, según los casos y la necesidad lo exijan. Por lo tanto, tengan bien entendido los gobernantes que mientras más vigorosamente reine el orden jerárquico entre las diversas asociaciones, quedando en pie y a salvo este principio de la función subsidiaria del Estado, tanto más firme será no sólo la autoridad sino también la eficiencia social, y tanto más feliz y más próspera la condición del Estado"3i.

"El Estado ha de saber permanecer dentro de los límites de su función subsidiaria de la iniciativa privada, secundarla, y según sean las necesidades ayudarla, pero no sustituirla cuando ella puede actuar y ser de utilidad y de éxito"3s. Cuando ella puede actuar y ser de utilidad y provecho, sí. $Y$ es que "es evidente que el logro de la vida económica no puede confiarse únicamente a la iniciativa privada, y mucho menos, como algunos quisieran, al libre juego de las fuerzas económicas. Tal doctrina se funda sobre una falsa concepción del Estado y del hombre, y conduce inevitablemente a aquella lucha de clases que muchas veces ha sometido a dura prueba el desarrollo gradual de la economia. Siendo el egoismo un hecho muy frecuente en este campo, corresponde al Estado, como promotor del bien común. llamar la atención de los individuos sobre sus deberes sociales, y regular, siempre dentro de los limites de lo justo y honesto, sus activi-

"Plo X1, Quadragesimo Anno cit. parágr. 79 (en Ds 732).

sPio XI, Quadragesimo Anno cit. parágr. 80 (en os 732-733).

${ }^{*}$ Pio XII, Discurio a la Confederación Italiana del Comercio (17.2.1956). Agregaba el más sabio de los pontifices de este siglo: "Entre los dos componentes del movimiento económico, las fuerzas del progreso y los elementos de organización, debe ser mantenido el equilibrio, si no se quiere caer en la anarquia o en el estancamiento". 
dades económicas en armonía con el bien colectivo. Error no menos funesto, sin embargo, sería atribuir al Estado la tarea o misión de planificar integralmente la vida económica, hasta la supresión de toda iniciativa privada, con el fin de conseguir el ideal de una quimérica igualdad entre los hombres. También en este campo la intervención del Estado es subsidiaria: su acción ha de estar informada por la justicia, no suprimiendo la iniciativa de los particulares, sino interviniendo sólo cuando y en la medida que lo exija el bien común, para estimularla y coordinarla, dejando a los ciudadanos y a las organizaciones menores las funciones que son capaces de desarrollar"39.

$Y$ es que "en la organización de la producción debe mantenerse intangible en todo su valor normativo el principio, defendido siem. pre por la doctrina social de Ia Iglesia, según el cual la actividad $y$ el rendimiento por parte de la sociedad tienen siempre únicamente un carácter de ayuda y deben limitarse estrictamente a asistir y com. plementar la actividad del individuo, de la familia y de los grupos profesionales" 10 .

${ }^{3}$ Pío xir, Carta de la Secretaria de Estado a la xxix Semana Social de Italia (Bérgamo - 22.9.1956). Esa sana interrención del Estado había sido ya defendida por León XiI (Rerum Novarım, parágr. 23 a 26) lo que recordaba bien Pio xı en su Quadragesimo Anno, parágr. 25: "Por lo que se refiere al poder civil. León XIII, desbordando audazmente los limites impues. tos por el liberalismo, enseña valientemente que no debe limitarse a ser un mero guardián del derecho y del recto orden, sino quc, por el contrario, debe luchar con todas sus fuerzas para que 'con toda la fuerza de las leyes y de las institucioncs. csto es haciendo que de la ordenación y adminis. tración misma del Estado, brote espontáneamente la prosperidad, tanto de la sociedad como de los individuos'. Lo mismo a los individuos que a tus familias, debe permitírseles una justa libertad de acción, pero quedando siempre a salvo el bien común y sin que se produzca daño a nadie".

Pío XII lo pondrá muy de relieve. con su profundidad caracteristica, en Benignilas el Humanitas cit. (parágr. 20 a 23). al decir: "El mismo orden absoluto de los seres y de los tines, que muestra al hombre como persona autónoma, es decir como sujeto de deberes y de derechos inviolables, rafz y término de su propia vida social, abarca también al Estado, como sociedad necesaria, revestida de autoridad, sin la cual no podria existir ni vivir". ( $\left.{ }^{20}\right)$; "establecidos sobre la misma base, la persona, el Estado, el poder público, con sus respectivos derechos, están tan intimamente unidos y vinculados entre si, que o se conservan o se arruinan al mismo tiempo"(").

wPio xil, Nous avons lu. Carta ai director de las Semanas Sociales de Francia, Charles Flory (18.7.1947), en Ds 1034, 
Y todo esto precisamente en razón del bien común, que es el fundamento último y constitucional del llamado principio de subsidiaridad. Bien común de la sociedad civil o política que, a su vez, está configurado e informado y aún determinado por la perfección del hombre, desde el instante en que el bien común de la sociedad -fin mismo de la sociedad- no es sino el desarrollo y perfección del hombre, de todos los hombres, y de todo el hombre" 41 .

Esa perfección del hombre - a la cual todo ser humano está llamado ${ }^{42}$ - y esa preeminencia que posee metafísicamente sobre todo lo

"Valga recordar aquí brevemente que las instituciones básicas o esenciales de la sociedad, tales como "el matrimonio, la familia, el Estado, la propiedad privada, tienden por su naturaleza a formar y desarrollar al hombre como persona, a protegerlo y a hacerlo capaz de contribuir, con su voluntaria colaboración y responsabilidad personal, al mantenimiento y al desarrollo, también personal, de la vida social" (Pío xII, Mensaje de Navidad - 24.12.1952). Y es que "el individuo es no solamente anterior a la sociedad por su origen, sino que es también superior por su destino. La sociedad en cuanto que está ordenada a la formación y desarrollo de los individuos, no es más que el medio universal querido por la naturaleza para poner a las personas en relación con otras personas... Cuando el hombre entra, por el nacimiento, en la sociedad está ya provisto por el Creador de derechos independientes" ("derechos que el individuo recibe inmediatamente del Creador, no de otro hombre, ni de grupos de hombres, no del Estado, ni de grupos de Estados, ni de ninguna autoridad política"); "despliega su actividad dándolos y recibiéndolos, y por su colaboración con los demás hombres, crea valores y obtiene resultados que él solo no sería capaz de obtener, y de los que no puede él mismo, como persona individual, ser portador. Estos nuevos valores manifiestan que la sociedad posee una preeminencia y una dignidad propias; pero estos mismos valores superiores (como la sociedad misma) están a su vez ordenados por la naturaleza al individuo y a las personas" (Pío xiI, Discurso al vil Congreso Internacional de Médicos Católicos - 11.9.1956). Como ya lo decía este mismo Papa (Mensaje de Navidad - 24.12.1944) "el hombre, como tal, lejos de ser el objeto y un elemento pasivo de la vida social es, por el contrario, y debe ser y permanecer, su sujeto, su fundamento y su fin", "raíz y término de su vida social". Esto, ciertamente, no significa que el hombre como miembro de la sociedad no esté obligado a cooperar al bien común, y sin excepción alguna, incluso debiendo asumir cuando sea necesario una participación activa en el gobierno de la cosa pública "que hoy no es ya privileg:o de unos pocos, sino deber de todos, en función de las responsabilidades de que están investidos" en orden al bien común (idem).

"2" Sed perfectos como vuestro Padre celestial es perfecto" (Evangelio de San Maico, 5.48). El llamado hecho a todo hombre, sea religioso o laico, a la perfección (santidad) es un imperativo que ha sido puesto de relieve 
creado, no tiene más base ni menor fundamento que en lo que desde antiguo (San León Magno ${ }^{43}$ ) ya se llamara la eminente dignidad del hombre, y que hoy, con variado signo en su utilización, no es sino la dignidad de la persona humana.

Pero esa dignidad sólo puede comprenderse cabalmente en una concepción cristiana, la única que le da sustento verdadero, real y suficiente.

"Cada hombre representa un valor trascendente y absoluto, porque el Autor de la naturaleza humana le ha dado un alma inmortal"44. Y es que esa dignidad "le ha sido conferida al hombre por Dios desde el origen"45. "La dignidad del hombre es la dignidad de la imagen de Dios" 46 , pues "Dios creó al hombre a imagen y semejanza suya; lo creó a imagen de Dios" (Génesis 1.26).

Pues bien, ello muestra muy claramente "el auténtico rostro del hombre, no sólo dueño de las cosas, sino sobre todo dueño de sí mismo y consciente de su destino trascendente, individual y social, y de sus responsabilidades de criatura hecha a imagen y semejanza de Dios"47. "Responsable de sus actos y de su destino, capaz de gobernaree por sí mismo y hallando en ello su más alta dignidad"48; y

siempre en la espiritualidad cristiana; sin remontarse a la época de los 1lamados Padres del desierto, valga recordar en cspecial respecto a los laicos, a San Francisco de Sales, en el siglo xvir (Introducción a la vida devota), y a Monseñor Escrivá de Balaguer, en el siglo xx (con su famosa obra Camino).

${ }^{43}$ Sermón 21.3 (en Mignc, Patrologiae Lalinac, tomo 54, 192-193): "recuerda, oh cristiano, tu dignidad; no quicras, una vez hecho participe de la naturaleza divina, volver a la antigua vileza con tu conducta desarre. glada. Acuérdate de qué Cabeza y de qué Cuerpo eres miembro".

${ }^{4}$ Pío xir, Discur o a los delegados de la Conferencia Internacional sobre relaciones humanas en la industria (4.2.1956).

45Pío xil Con sempre cit. parágr. 35 (en DP 850). "Quien desea que la estrella de la paz aparezca y se detenga sobe la sociedad-dirá bellamente el Papa- contribuya por su parte a devolver a la persona humana la diz. nidad que Dios le concedió desde el principio; opóngase a la excesiva aglomeración de los hombres, así a mancra de masas sin alma; a su inconsis. tencia económica, social. política, intelectual y moral; a su faha de sólidos principios y de fuertes convicciones; a su cobreabundancia de excitaciones instintivas y sensibles, y a " $" 1$ colubilidad".

"ePio XII, Benignilas cit. parágr. 22 (en DP 877).

"Pío XII, Discurso a los participantes al Congreso de Asociaciones americano-europeas (18.9.1955).

"Pio Xil, Respuesta al cuerpo diplomático en su saludo anual (4.3.1956). 
puesto que es espiritu creado a imagen de Dios, con un alma inmortal recibida de su Creador, "el hombre es un ser personal, dotado de inteligencia y de libre albedrío, un ser que, en definitiva, decide por si mismo lo que hace y lo que deja de hacer"49.

En último término, y debe insistirse mucho en esto, la dignidad del hombre no se funda, ni tiene otra base que en Dios. Apartado Dios de una concepción del hombre, queda éste reducido a mero instrumento de otros hombres, o de la sociedad; incluso deviene en tal caso ironía cuando no sarcasmo hablar siquiera de dignidad50.

Dignidad de la persona, con sus derechos anteriores a la sociedad y al Estado, pero también con sus deberes y especialmente deberes sociales, pues está inclinada por su propia naturaleza a la vida en sociedad; sociedad donde encuentra las posibilidades de su propia perfección, tanto en el orden temporal como asimismo en su destino trascendente, vocado como está a la eternidad. Dicha sociedad, que establece una verdadera unidad moral entre todos sus miembros, tiene por objetivo, misión o fin, el bien común temporal, es decir el desarrollo y perfección del hombre, puesto que está naturalmente ella ordenada a la persona. Ahora bien, es la autoridad pública, es el Estado, el gerente nato de ese bien común; su oficio y fin propio, específico y esencial es precisamente el bien común, y es que la autoridad estatal ha sido constituida con el único fin de promover el bien de todos sus miembros, a su desarrollo y perfección en el orden temporal, indispensable para obtener su propio fin y último, fin de la persona que es trascendente.

De alli que para obtener ese bien común de la sociedad, en lo temporal, el Estado, la autoridad pública ha de intervenir, y ha de

\footnotetext{
"Pío XII, Discurso a los miembros de la Comision Internacional de Policia Criminal (15.10.1954).

"Ya León XIII (Rerum Novarum cit.) afirmaba con significativa firmeza y clarividencia: "a nadie le está permitido violar impunemente esta dignidad del hombre que el propio Dios trata con tan grande respeto"; "es vergonzoso e inhumano usar a los hombres cual viles instrumentos de lucro y no estimarlos más que en proporción al vigor de sus brazos" (parágr. 14 y 30; en os 325 y 341 s., respectivamente).
} 
hacerlo precisamente para el bien común, de todos y cada uno de los ciudadanos que lo componen, observando al efecto la justicia distri: butiva, que es la justicia propia de la autoridad cuando ejerce su mitión de distribución o reparto de ese bien común.

Pues bien, la forma o formas que puede asumir esa intervención estatal (y donde aparece el principio de subsidiariedad con todas las virtualidades de su fuerza de principio $^{51}$ ) ha de estar - si se quiere que sea provechosa, útil y, en especial, promotora del bien comúnfundamentada, como emanación de la prudencia política que es la virtud del gobernante, en las circunstancias de tiempo, lugar y situaciones concretas que una determinada sociedad depare. Pero en caso alguno, si quiere tener éxito o eficacia verdadera, podrá apartarse esa intervención de la finalidad misma que persigue, que es el bien común temporal de la sociedad, de los miembros que la componen, de la naturaleza misma del hombre: ser individual creado a imagen de Dios, libre y responsable de su propio fin, llamado a un destino trascendente, que lo busca y obtendrá en sociedad, viendo en cada pró. jimo esa imagen de Dios, que él mismo porta, lleva y trasluce como la marca más extraordinaria y también más enteramente gratuita con que ha querido regalarle como señor de la creación el mismísimo Au. tor de todo lo creado.

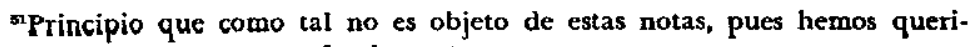
do aqui sólo mostrar sus fundamentos. 